Old Dominion University

ODU Digital Commons

Counseling \& Human Services Faculty

Publications

Counseling \& Human Services

2021

\title{
Institutional Responses to the COVID-19 Pandemic: Faculty and Administrator Experiences
}

\author{
Narketta Sparkman-Key \\ Old Dominion University, nsparkma@odu.edu \\ Tammi F. Dice \\ Old Dominion University, tmillike@odu.edu \\ Alexandra C. Gantt \\ Old Dominion University, agant002@odu.edu
}

Follow this and additional works at: https://digitalcommons.odu.edu/chs_pubs

Part of the Educational Psychology Commons, Higher Education Commons, and the Online and Distance Education Commons

Original Publication Citation

Sparkman-Key, N., Dice, T. F., \& Gantt, A. (2021). Institutional responses to the COVID-19 pandemic: Faculty and administrator experiences. Current Issues in Education, 22(3). https://doi.org/10.14507/ cie.vol22iss3.1993

This Article is brought to you for free and open access by the Counseling \& Human Services at ODU Digital Commons. It has been accepted for inclusion in Counseling \& Human Services Faculty Publications by an authorized administrator of ODU Digital Commons. For more information, please contact digitalcommons@odu.edu. 


\title{
Current Issues in Education
}

Mary Lou Fulton Teachers College • Arizona State University

PO Box 37100, Phoenix, AZ 85069, USA

\section{Institutional Responses to the COVID-19 Pandemic: Faculty and Administrator Experiences}

\author{
Narketta Sparkman-Key \\ Old Dominion University \\ Tammi F. Dice \\ Old Dominion University \\ Alexandra C. Gantt \\ Old Dominion University
}

\begin{abstract}
The onset of the COVID-19 pandemic required shifts in operations for institutions of higher education everywhere. Faculty and administrators were asked to adapt to meet the needs of students. We conducted a qualitative content analysis to understand institutional responses and examine the experiences of faculty and administrators during the COVID-19 pandemic through the lens of chaos theory. Institutional responses to the pandemic varied. Participants identified supports and resources deemed helpful, as well as those found to be inadequate or unwanted. We also found that the pandemic resulted in some positive outcomes for faculty and administrators, which led to growth in teaching and self-care. Implications for strategic planning and future directions for research are explored.
\end{abstract}

Keywords: COVID-19, disaster preparation, higher education, institutional response, faculty support

Citation: Sparkman-Key, N., Dice, T.F., \& Gantt, A.C. (2021). Institutional responses to the COVID-19 pandemic: Faculty and administrator experiences. Current Issues in Education, 22(3). https://doi.org/10.14507/cie.vol22iss3.1993

Accepted: October/9/2021

\section{Institutional Responses to the COVID-19 Pandemic: Faculty and Administrator Experiences}

To date, over 756,962 COVID-19-related deaths have been reported in the United States (Centers for Disease Control and Prevention [CDC], 2021). Amidst the tragedies and unknowns of the pandemic, university faculty, students, and administrators experienced major transitions in both their personal and professional lives as institutions of higher education across the country 
transitioned to remote learning environments to reduce the spread of the virus. Such transitions, coupled with personal and collective traumas and stressors, warrant exploration of impact, both professionally and emotionally. Holmes and colleagues (2020) called for exploration of related mental health effects and potential mitigation on the general population, while other researchers have specifically called for exploration of the impact of education's transition from residential to remote learning on university faculty (Watermeyer et al., 2020). With awareness of the multiple stressors facing university faculty and the pressing need for faculty support, we conducted a qualitative content analysis and engaged chaos theory to better understand faculty experiences and needs in response to the COVID-19 pandemic.

\section{The Effects of COVID-19}

The Novel Coronavirus Disease 2019, or COVID-19, was recognized by the World Health Organization (WHO) in December of 2019 and is associated with a variety of physical and mental health outcomes at both individual and community levels (Fauci et al., 2020; von Braun et al., 2020; WHO, 2020). Impacts of the pandemic have disproportionately affected marginalized populations (von Braun et al., 2020) and brought attention to the need for preventative work regarding infectious disease outbreak (Fauci et al., 2020). Americans have also experienced various challenges related to job loss and economic insecurity due to the pandemic. For example, according to a study by Parker et al. (2020), 25\% of adults have reported having trouble paying their bills since the COVID-19 outbreak, 17\% have sought food from a food bank, and 50\% of individuals who lost their jobs because of the pandemic remain unemployed. Mental health outcomes appear similarly troubling. Pfefferbaum and North (2020) highlighted some possible mental health impacts of the pandemic, including: insecurity, feelings of isolation, emotional distress, increased substance use/abuse, insomnia, and fear. Pfefferbaum and North also noted how negative mental health outcomes may disproportionately affect individuals from certain groups, such as the elderly, and called for "...already stretched health care providers...to [monitor the] psychosocial needs" of their patients (para. 11). Others have also emphasized the critical need for future research to examine the mental health implications of the pandemic (Roy et al., 2020; Torales et al., 2020).

\section{COVID-19 and Higher Education}

Considering the wide-ranging implications of the COVID-19 pandemic, it is plausible to consider potential impacts on higher education, specifically on university faculty and administrators. Such impacts would be far-reaching, given the 4,234 higher education institutions and over 25 million college students in the United States (Entangled Solutions, 2020). Watermeyer et al. (2020) engaged a sample of over 1,000 university faculty in the United Kingdom to explore their thoughts and feelings regarding the transition from residential to online learning due to the pandemic. Participants reported negative outcomes, including distrust of remote learning, and the researchers noted: "online migration is engendering significant dysfunctionality and disturbance to [university faculty's] roles and their personal lives" (p. 1).

Other challenges to faculty members during the pandemic are related to work-life balance and changes in job responsibilities (Watermeyer et al., 2020). Moreover, researchers have found disproportionate effects of the pandemic regarding gender, with female faculty members experiencing decreased research productivity compared to males (Cui et al., 2020). Media outlets have also begun to explore the impact of COVID-19 on academia, suggesting chronic faculty 
stress, perceptions of work as more difficult, and even experiences of secondary trauma (Flaherty, 2020).

Thus, in the present qualitative study, we engaged chaos theory to increase understanding of the needs of faculty in higher education in response to the COVID-19 pandemic and sought to answer the following research questions: (1) What accommodations have been implemented by universities for university faculty and academic administrators to adapt to the COVID-19 pandemic? and (2) How have faculty and academic administrators responded to the changes stemming from the COVID-19 pandemic?

\section{Theoretical Framework}

Relative to the field of psychology, chaos theory is defined by Ayers (1997) as "a systems approach which looks at process and not a static state, examining the change or movement of systems" (p. 374). Chaos theory maintains that systems are deeply complex, interconnected, nonlinear, and affected even by small changes (Chamberlain \& Butz, 2016). Additionally, Chamberlain and Butz (2016) described movement away from equilibrium within a system as an increase in chaos, possibly including increased opportunity for reorganization, new choices, and general change. The theory has been used in framing the impact of pandemics (Chamberlain \& Butz, 2016) and in understanding higher education leadership, planning, and policy (Swenk, 2001).

Moreover, chaos theory does not refer to total randomness or pandemonium as some may assume by the title; rather, the theory is concerned with varying behavior, meaning one cannot predict what will exactly happen in the future (Swenk, 2001). The theory describes a system as being influenced by internal feedback (Swenk, 2001). Feedback loops within an institution modify the system and predictability is only possible in short time frames. Constant change, unpredictability, instability, and disequilibrium are expectations for a system (Swenk, 2001).

In higher education, chaos theory has been applied to strategic planning within this complex system (Cutright, 2001). Relative to the current COVID-19 pandemic, chaos theory "implies that a small change of one parameter (e.g., length of lockdowns) might create a very different outcome on many variables; thus, various aspects that interact with each other have to be taken into account" (Zenker \& Kock, 2020, p. 2). Zenker and Kock (2020) called for future researchers to explore the impacts of related chaos on complex system outcomes during the COVID-19 pandemic. Inside Higher Ed (2020) partnered with Gallup to examine the financial impact of the pandemic on higher education institutions. Many institutions immediately lost sources of revenue (e.g., campus housing and sports) while concurrently assuming increased expenses to meet technology demands of both students and staff with the migration to remote work and online learning (Anderson and Alonso, 2020). Through a survey of university presidents, researchers found that $70 \%$ of participants felt that their institution needed to make fundamental changes to its business model, programming, and other operations (Inside Higher Education, 2020). The pandemic has seemingly produced fears for the future and effective strategic planning could help institutions reduce those fears.

Strategic planning is an "attempt to systematize the processes that enable an organization to achieve goals and objectives" (Crittenden, 2000 as cited in Goldman and Salem, 2015). Academic institutions engage in strategic planning in a variety of ways. Hinton (2012) suggests that the mission of the institution be the foundation of higher education strategic planning. The supporting components of the strategic plan are the values, institutional goals, and vision. The plan itself includes operational goals, objectives, and an implementation plan. According to 
Goldman and Salem (2015), the general structure of strategic planning is like a pyramid. At the very top is the university vision, followed by the university mission, and then specific goals, objectives, and key performance indicators.

The environment, both inside of the institution and external to the institution, informs each level of the pyramid because the environment can impact the strategic planning process and the goals initiated within the plan. Institutions often do an analysis of the environment prior to beginning the planning process (Alexander \& Alonso, 2020). Some universities begin by appointing a strategic planning committee which assumes the role of initiating the strategic planning process. However, this can vary by institution.

Capturing the voice of key stakeholders is an important aspect of planning and this is typically done through focus groups (Nutefall, 2015). Focus groups and/ or open forums are used at multiple phases in the planning process typically to provide feedback on the vision/mission, and goals and objectives of the strategic plan. In addition, some institutions hire outside consultants to assist in the strategic planning process, finding that they garner greater participation from stakeholders when an outside consultant is used (Nutefall, 2015).

Communication and implementation plans are often developed in conjunction with the strategic plan. This helps to ensure there is a streamlined process for communication of information related to the plan and for garnering support from key stakeholders. The common element of these strategies is the notion that the mission and vision of the institution is the foundation of the plan.

In the present study, chaos theory is applied with regard to how it informs strategic planning within higher education by accounting for the complexity of institutions and the impact of change on those institutions. Change in this study is defined in terms of the impact the pandemic has had on institutional operations and key stakeholders. According to Cutright (2001), Chaos theory has ten propositions that frame the basis for strategic planning. Each proposition informs institutions of guidelines critical in strategic planning and preparing for change that can impact institutional goals. These guiding propositions are outlined in Table 1. Each of these propositions detail foundational guidelines for effective strategic planning. The impact of the COVID-19 pandemic on higher education institutions presents an opportunity to better prepare for the future.

In this study, we considered participants' experiences within and in relation to their institutional response to the pandemic, academic work environments, personal health, family systems, and social contexts during the time of the COVID-19 pandemic. Chaos theory is applicable to the conceptualization of university faculty and administrators' experiences during the COVID-19 pandemic due to the rapidly changing nature of the university environment currently, along with the influences of innumerable other personal and collective factors. Chaos theory is also applicable because of its use in strategic planning within higher education which can assist institutions in planning after the impact of the pandemic. Results of this study can be used to help shape strategic planning for institutions moving forward. 


\section{Table 1}

The 10 Propositions of Chaos Theory

\begin{tabular}{ll}
\hline Proposition & \multicolumn{1}{c}{ Definition } \\
\hline 1 & "The ideal outcome of planning is planning, not a plan" (p. 61) \\
\hline 3 & "Planning begins with a distillation of the institution's key values and purposes" \\
(p. 62) & "The widest possible universe of information should be made available to all \\
& members of the institution. This universe of information includes ongoing, rich, \\
and current feedback" (p. 64)
\end{tabular}

Note. Adapted from Cutright, M. (2001). Chaos theory \& higher education: Leadership, planning, \& policy. Higher education: Questions about the purpose (s) of colleges \& universities. Volume 9. Peter Lang. https://doi.org/10.1023/A:1017978827715

\section{Method}

Using qualitative content analysis, we examined participants' responses to open-ended survey questions to gain insight into the experiences, perceptions, and overall mental health of college and university faculty and administrators amid the COVID-19 pandemic. A qualitative approach was selected due to the dearth of information currently known about universities' responses to COVID-19 and the impacts on university faculty and administrators (Hunt, 2011). Qualitative content analysis was best suited for this study as it is a "research method for the subjective interpretation of the content of text data through the systematic classification process 
of coding and identifying themes or patterns" (Hsieh \& Shannon, 2005, p. 1278). Specifically, conventional content analysis was used with the intent to derive themes inductively from the raw data to describe the experiences of the faculty and administrators (Hsieh \& Shannon, 2005; Zhang \& Wildemuth, 2005). This approach allows for both quantifying coded data and qualitatively interpreting the quantitative counts of the codes.

\section{Participants}

We utilized purposeful sampling methods to recruit participants through email and listserv postings, and asked participants to meet the following criteria: over 18 years of age and currently employed as a faculty member or academic administrator at a college or university. More specifically, we utilized a random university generator to select university departments in the United States, and then retrieved faculty emails from the respective department webpages to request participation. We emailed 1,000 individual potential participants in total. Other means of recruitment included emails to various faculty email listservs (e.g., CESNET) and posts to faculty Facebook and LinkedIn groups. Ultimately, 212 respondents met the criteria, consented to participate, and were included in the study. Of these, $70.3 \%(n=149)$ identified as female, while $29.2 \%(n=62)$ identified as male and $.5 \%(n=1)$ as non-binary. Most participants $(34.4 \% ; n=73)$ were between the ages of 51 and 64 years old. The remaining $27.4 \%(n=58)$ were between $29-40$ years old, $23.6 \%(n=50)$ were $41-50$ years old, $11.8 \%(n=25)$ were 65 or older, and $1 \%(n=2)$ were between the ages of 18 and 28 . Four participants did not report their age. Ninety percent $(n=191)$ of participants identified as White, while the remaining $10 \%$ identified as a racial minority ( $n=8$ African American, and $n=9$ Asian) or declined to answer $(n=4)$. Seventeen participants $(8 \%)$ identified as Hispanic, Latino or of Spanish Origin. The majority $(72.2 \% ; n=153)$ reported they were married and $89(42 \%)$ indicated caring for children in the home.

Participants also provided information pertaining to their primary job positions. The majority were tenured or tenure eligible faculty with $27.4 \%(n=58)$ identifying as assistant professors, $25 \%(n=53)$ as full professors, and 25\% $(n=53)$ as associate professors. Faculty respondents also included lecturers/instructors $(8.5 \% ; n=18)$ and adjunct instructors $(8 \% ; n=$ 17). Administrators made up $7.1 \%(n=15)$ of participants. Two indicated dual roles as faculty and administrator. A little over half $(54.5 \% ; n=114)$ of participants reported working for public colleges and universities, and the remaining were affiliated with private colleges and universities. Most participants $(50 \% ; n=106)$ reported being employed by a large college or university (at least 15,000 students). Those at mid-size institutions (5,001-14,999 students) accounted for $29.2 \%(n=62)$ of respondents, and those at small institutions $(5,000$ or fewer students $)$ accounted for $20.8 \%(n=44)$. Variations also existed by type of institution: $44 \%(n=93)$ were teaching institutions, $31.1 \%(n=66)$ were $\mathrm{R} 1,19.3 \%(n=41)$ were $\mathrm{R} 2,5 \%(n=10)$ by another type of institution (such as a community or technical college), and $1 \%(n=2)$ declined to answer. Finally, faculty and administrators from colleges and universities in the Southeastern United States accounted for $41 \%(n=87)$ of respondents. The remaining $23.1 \%(n=49)$ were from the Midwest, $14.2 \%(n=30)$ from the Northeast, $8.5 \%(n=18)$ from the Northwest, $7.5 \%$ $(n=16)$ from the West, and $6 \%(n=12)$ from the Southwest.

\section{Data Source}

The data set for this study consisted of open-ended responses to a survey taken by participants via Qualtrics, an online survey software. The questions included: (1) What 
accommodations, if any, has your department/university made for faculty due to the pandemic?; (2) If any, please list accommodations and/or resources that would be helpful during this time that your department/university has not provided; (3) Please describe any coping strategies you have utilized while working at home; and (4) What skills, attitudes, or ideas have you gained/learned from your experience working remote that you will continue to apply postpandemic?

\section{Procedure}

The university's institutional review board provided exempt status for the study. We then sent the survey, including demographic questions and the four open-ended questions, to faculty and administrators throughout the United States via emails directly to faculty members, to department chairs for dissemination, and to listserv postings. We sent three follow-up emails encouraging individuals to participate in the study to promote data saturation. Efforts were taken to ensure that participants were not coerced to participate; specifically, participants were provided an informed consent form and assured that confidentiality would be maintained. No identifying information was used when quoting participants in this article. All survey responses, data, and analyses were maintained on a password-secured computer.

\section{Data Analysis}

The responses to each of the four open-ended items on the survey were analyzed separately. We followed Hsieh \& Shannon's (2005) procedures for conventional content analysis. Two of the authors participated in the analyses to enhance credibility through researcher triangulation (Elliott et al., 1999). Initially, we immersed ourselves in the raw data to gain an overall sense of responses. Each researcher maintained an independent code book to record the data and note frequency of responses by hand. The codes included key words and phrases that were recorded directly and inductively from the raw data without imposing preconceived perspectives or categories. The coded data was then organized into preliminary categories and patterns. Each researcher maintained a research memo to note reflections pertaining to the codes and emergent categories and patterns. We then came together for consensus coding. The independent code books were compared, and congruity and inconsistencies were discussed. Meaningful and consistent themes and subthemes were defined. See the Appendix for the final code book. Themes that emerged were supported with verbatim quotes to mitigate researcher bias (Hsieh \& Shannon, 2005). The third author reviewed the analyses and confirmed the emergent themes.

\section{Results}

Themes emerged in each of the four open-ended questions on the survey. The first question produced three themes, the second produced five, the third produced four, and the fourth produced three.

\section{Question 1: Institutional Response}

Three themes emerged from the first question on the survey which asked, "What accommodations has your department/university made for faculty due to the pandemic?" The themes addressed professional adaptations (subthemes: teaching and work), professional supports (subthemes: technology, information, materials, and funding), and no/minimal or 
unwanted accommodations. See Table 2 for an overview of the themes and subthemes for question 1.

Table 2

Question 1: What accommodations were made for faculty?

\begin{tabular}{c|c|c|l}
\hline Theme & Freq. & $\%$ & \multicolumn{1}{|c}{ Summary } \\
\hline $\begin{array}{c}\text { 1. Professional Adaptations } \\
\text { Teaching adaptations }\end{array}$ & 151 & 53.4 & \\
Work adaptations & 72 & & $\begin{array}{l}\text { Choice of online or face to face } \\
\text { teaching; or full shift to online; } \\
\text { online teaching trainings } \\
\text { Teleworking; extending the } \\
\text { tenure clock; eliminating } \\
\text { course evaluations; extending } \\
\text { deadlines }\end{array}$ \\
$\begin{array}{ccc}\text { 2. Professional Supports } \\
\text { Technology resources }\end{array}$ & 95 & 33.6 & \\
Materials & 14 & & Equipment; technology support \\
Information & 7 & & Office supplies at home; \\
Funding & & & COVID resources such as PPE \\
& & & Meetings; email \\
& & & Stipends; reimbursements \\
3. No/minimal/unwanted & 283 & 100.0 & \\
\hline
\end{tabular}

Note. Since many responses had more than one code applied to them, the total frequency will be more than the total number of respondents.

The first theme of professional adaptations, shared by $53.4 \%$ of participants $(n=151)$, consisted of two subthemes. The first addressed teaching adaptations such as accommodations to teaching formats in which faculty were permitted to choose whether they wished to teach faceto-face, hybrid or fully online, or all courses were transitioned fully online. This sub theme also included online teaching trainings provided by institutions. The second sub theme addressed work adaptations and included accommodations such as a shift to teleworking, as well as flexibility regarding extending the clock for tenure and pre-tenure review, eliminating course evaluations for the spring semester, and extending deadlines for things such as grading. Quotes included, "Full shift to online teaching...," "Many online teaching resources/trainings...," "Allowed fully remote work," and "Option to postpone going up for tenure." 
The second theme of professional supports was apparent in $33.6 \%(n=95)$ of participants' responses. It consisted of four subthemes. The first of which addressed technology resources, including both equipment, such as access to laptops, headsets, and software, and support, such as troubleshooting issues and providing trainings for the use of technology such as Zoom. The second sub theme addressed material supports such as office supplies being sent to faculty's homes for teleworking and access to COVID-related resources, such as personal protective equipment (PPE). The third sub theme included supportive information through meetings and email, particularly from administrators, and the final sub theme addressed the provision of funds through stipends and reimbursements. Participants stated, "Faculty receive PPE and online teaching kits (hardware)," "Lots of IT support," "They offered us training on Zoom," "Dean hosts weekly zoom meeting to discuss and update," and "Assistance with personal phone bill and assistance with stationary supplies."

The third and final theme for this question was "no/minimal or unwanted accommodations" and was expressed by $13 \%(n=37)$ of participants. These individuals felt that their institutions had done very little to nothing to address the pandemic. The sentiment was captured in the following: "Unknown, it seems like we have all been on our own," "None, other than working from home," and "None. There was only more work added."

\section{Question 2: Additional Supports}

Five themes emerged from the second item on the survey which stated: "If any, please list accommodations and/or resources that would be helpful during this time that your department/university has not provided." The themes addressed technology, enhanced system support, no accommodations needed or not sure what is needed, manageable workload, and teaching. See Table 3 for an overview of the themes and subthemes for question 2.

The first theme, technology, was addressed by $25.5 \%(n=36)$ participants. These individuals expressed a desire to have more access to equipment and training. One participant stated, "Not all faculty have laptop/digital tools needed; hardware has been very slow to be disseminated." Another specified, "Definitely better technology, and better tech support."

Enhanced system support, the second theme, was highlighted by $23.4 \%(n=33)$ of participants and included things such as desiring better communication from leadership, mental health supports, financial support, and COVID-19 safety measures. These were captured in the following quotes: "Mental health check-ins for faculty (they did it with students, but not faculty)," "More money, or at least, you know, not being furloughed," "...more consistent and detailed communication," and "More masks!"

The third theme which emerged was that no other accommodations were needed, or that participants were not sure what else was needed. This was expressed by $19.1 \%(n=27)$ of participants and captured in the following: "Nothing comes to mind," "None needed," and "Unknown at this time."

The fourth theme, manageable workload, was addressed by $16.3 \%(n=23)$ of participants and included support with balancing childcare with work, and reducing nonessential work and meetings so more time would be available for adjusting to online teaching and maintaining research. Participants stated: "Identifying which faculty have childcare or other caregiving responsibilities that impact their daily schedule and designing accommodations- e.g., lessen service work," and "More protection of our time to do research for pre-tenure faculty."

The fifth and final theme for this question addressed teaching accommodations that would have been helpful, such as additional online teaching trainings, graduate teaching 
assistants, and being able to select a preferred teaching modality. These were highlighted by $15.6 \%(n=22)$ of participants. Statements included, "Better training on hybrid course design," "Access to a graduate assistant," "TA [teaching assistant]," and "Autonomy over whether classes are moved online for the fall."

Table 3

What accommodations would be helpful that have not been provided?

\begin{tabular}{l|c|c|l}
\hline \multicolumn{1}{c|}{ Code } & Freq. & $\%$ & \multicolumn{1}{c}{ Summary } \\
\hline 1. Technology & 36 & 25.5 & Greater access to equipment and training \\
2. Enhanced system support & 33 & 23.4 & $\begin{array}{l}\text { Better communication, mental health } \\
\text { supports, financial support, and COVID safety } \\
\text { measures }\end{array}$ \\
3. None needed/not sure & 27 & 19.1 & $\begin{array}{l}\text { No accommodations needed or unsure of what } \\
\text { needed } \\
\text { 4. Manageable workload }\end{array}$ \\
5. Teaching & 22 & 16.6 & $\begin{array}{l}\text { Support to balance childcare; reducing } \\
\text { nonessential meetings and work } \\
\text { Online teaching trainings; GAs, select } \\
\text { teaching modality }\end{array}$ \\
\hline Total & 141 & 100 & \\
\hline
\end{tabular}

Note. Since many responses had more than one code applied to them, the total frequency will be more than the total number of respondents.

\section{Question 3: Coping Strategies}

Four themes emerged from the third item on the survey which stated, "Please describe any coping strategies you have utilized while working at home." The themes addressed activities (with sub themes including physical, social, and enjoyable), mental health boosters, work habits, and not using any/none needed. See Table 4 for an overview of the themes and subthemes for question 3.

For the first theme, activities, $58.9 \%(n=219)$ of participants shared endeavors in which they have engaged to cope while teleworking that fell into three subthemes: physical, social, and enjoyable. Physical activities included exercising, going for walks, practicing yoga, and gardening. Social activities included connecting with friends and family, engaging with colleagues, and continuing writing groups via Zoom. Many examples of enjoyable activities were provided, including watching TV or movies, baking, playing with pets, reading for pleasure, playing and/or listening to music, engaging in crafts and hobbies, and playing games. This sub theme also included indulgences such as eating junk food and drinking wine. Activities were addressed in the following statements: "Going outside daily and taking lots of walks. Zoom meetings with family and friends," and "Going for walks, cooking, staying connected to friends." 
The second theme, mental health boosters, was identified by $24.2 \%(n=90)$ of participants. These included stress reducing techniques such as taking breaks, practicing patience, gratitude and self-compassion, engaging in prayer and meditation, and setting limits around watching the news and social media. Participants specified the following: "Taking breaks from the computer when needed," "Daily meditation," "Taking "news vacations'," and "Practicing gratitude - particularly being thankful I have a job."

Theme three addressed work habits used to help cope. These were identified by $14 \%$ ( $n=$ 52) of participants and included strategies such as following a set schedule, creating a separate space in their home for work, and managing the dual roles of work and childcare. One participant said they were coping by, "designating a workspace from home space, maintaining a set schedule, and dressing as if [she were] going to work." Another expressed coping by "developing a new schedule/routine, alternating childcare responsibilities with partner."

For the final theme, a smaller percentage of participants indicated that they weren't using coping strategies or didn't need any $(3 \% ; n=11)$. Several individuals responded, "None," or "N/A." For these, it is impossible to know whether they indicated not using coping skills because they did not need them or if they were not using them but should. Others clarified their lack of use with statements such as, "Minimal without childcare," indicating the challenge of utilizing coping strategies when balancing work and parenting. Others indicated that coping strategies were not needed with statements such as, "I usually work from home, so to me, this was a no big deal type of situation."

\section{Table 4}

Coping strategies utilized

\begin{tabular}{|c|c|c|c|}
\hline Code & Freq. & $\%$ & Summary \\
\hline $\begin{array}{l}\text { 1. Activities } \\
\text { Physical } \\
\text { Social } \\
\text { Enjoyable }\end{array}$ & $\begin{array}{l}219 \\
111 \\
45 \\
63\end{array}$ & 58.9 & $\begin{array}{l}\text { Exercise; walks; yoga; gardening } \\
\text { Connecting with friends and family; engaging } \\
\text { colleagues; writing groups } \\
\text { TV/movies; baking; pets; reading; music; hobbies; } \\
\text { games; food and drinks }\end{array}$ \\
\hline 2. Mental health boosters & 90 & 24.2 & $\begin{array}{l}\text { Stress reduction techniques; prayer and meditation; } \\
\text { limiting exposure to news and social media }\end{array}$ \\
\hline 3. Work habits & 52 & 14.0 & $\begin{array}{l}\text { Setting a schedule; creating work space; managing } \\
\text { childcare }\end{array}$ \\
\hline 4. Not using any/no need & 11 & 3.0 & Not applying coping skills \\
\hline Total & 372 & 100 & \\
\hline
\end{tabular}

Note. Since many responses had more than one code applied to them, the total frequency will be more than the total number of respondents. 


\section{Question 4: Growth and Learning}

Three themes emerged from the fourth and final question on the survey which asked, "What skills, attitudes, or ideas have you gained/learned from your experience working remotely that you will continue to apply post-pandemic?" The themes addressed teaching skills, professional insights, and personal insights. See Table 5 for an overview of the themes and subthemes for question 4 .

\section{Table 5}

Skills, attitudes, ideas gained that you will continue post-pandemic

\begin{tabular}{l|c|c|l}
\hline \multicolumn{1}{c|}{ Code } & Freq. & $\%$ & \multicolumn{1}{c}{ Summary } \\
\hline 1. Teaching skills & 89 & 48.9 & $\begin{array}{l}\text { Online teaching tools; connecting with students; } \\
\text { teaching more online or not teaching online }\end{array}$ \\
2. Professional insights & 55 & 30.0 & $\begin{array}{l}\text { Continue meeting online; maintaining a set } \\
\text { schedule }\end{array}$ \\
3. Personal insights & 38 & 20.1 & Realizing adaptability; importance of self-care \\
\hline Total & 182 & 100 & \\
\hline
\end{tabular}

Note. Since many responses had more than one code applied to them, the total frequency will be more than the total number of respondents.

The first theme of teaching skills was shared by $48.9 \%(n=89)$ of participants. They addressed continuing to use more online teaching tools, regardless of modality. They also expressed a desire to continue to take strides to connect more with their students and be more flexible and empathic. Some realized they would like to continue teaching more online courses while others realized online teaching is not for them. One respondent stated:

Just pertaining to teaching, I have learned many ideas and approaches that I think will improve my teaching whether online or on ground. The situation has forced us to reexamine assumptions about what we do and online makes many of us who taught mainly on ground to rethink how you make connections with students, structure courses, and prepare students for challenging situations.

Another said, "Spending more time with students, being a little less task-focused and a little more person-focused."

Professional insights, the second theme, accounted for 30\% $(n=55)$ of responses. Participants expressed a desire to continue meeting online either in place of or in addition to face-to-face. This was captured in the following statement, "Administrative meetings can be more conveniently scheduled as video calls." Another said, "Zoom meetings are, overall, as efficient or more efficient than face to face meetings." Some also intend to continue to work more from home. A respondent said, "I will likely do more work from home because I'm confident I can be productive now." Being more organized and maintaining a set schedule with 
boundaries to the workday was shared as well. Participants stated, "Time management," and "Setting workday schedule and stopping."

The final theme addressed personal insights and was expressed by $20.1 \%(n=38)$ of participants. These participants reportedly experienced a shift in perspective. There was a realization of how adaptable they were, and how important it is to engage in self-care and practice setting more realistic expectations for themselves. One participant shared, “...the unplugged coffee time, bullet journaling, and more intentional gratitude practice are something I hope to keep applying." Others said, "I must take care of myself," and "Resiliency and grace!"

\section{Discussion}

Findings from this study indicate that institutional responses to the COVID-19 pandemic varied and resulted in mixed experiences for faculty and administrator participants. Some expressed feeling supported and well resourced, while others felt uninformed, unheard, and under-supported. When asked about accommodations made by institutions, participants identified professional adaptations in the form of modified teaching and work expectations, and professional supports such as additional technology, information, materials, and funding. However, $15 \%$ of participants reported that their institutions had not offered any accommodations or had instituted accommodations that were burdensome or unwanted. The lack of accommodations could indicate that some institutions felt ill prepared for the impact of the pandemic or unaware of what accommodations were needed. Burdensome or unwanted accommodations could indicate limited resources to meet the needs or unaware of what the needs were. These factors could also be an indication of the lack of preparedness to address the demands that resulted from the impact of the pandemic. Chaos theory implies that a small change could create different outcomes on many variables, and all variables that interact must be considered (Zenker \& Kock, 2020). Employing feedback loops among all stakeholders, as suggested by chaos theory, could possibly have prevented institutions from invoking burdensome and unwanted resources, and promoted application of helpful resources.

To address state and national requirements to social distance, quarantine, and slow the spread of the COVID-19 virus, institutions of higher education across the country responded quickly and instituted accommodations to allow for courses to continue, albeit online.

Researchers found that the pandemic negatively impacted individuals across disciplines, which aligns with our findings concerning negative faculty experiences such as perceived lack of support and a dearth of accommodations. Pfefferbaum and North (2020) highlighted mental health impacts of the pandemic, while Watermeyer et. al. (2020) noted challenges with work-life balance due to changes in job responsibilities. These findings may help explain our findings surrounding the perceived increased need for university-provided supports, as well as negative feelings of stress and lack of support. Additionally, Cui et. al. (2020) reported disproportionate effects of the pandemic on female faculty members experiencing decreased research productivity compared to males, while Flaherty (2020) noted chronic faculty stress, negative perceptions of work, and experiences of secondary trauma being perpetuated because of the pandemic. In line with the findings of these studies, participants in the present study noted various changes in personal and professional functioning, needs, and related changes in ways of thinking about themselves and their jobs. Though limited, the extant literature seems to consistently suggest the need for universities to be prepared to respond to crises in support of their faculty, both professionally and regarding mental health. 
Accommodations and adaptations were necessary steps in meeting the needs of the university community. However, developing strategies to meet these needs without first gathering employee input could have led to accommodations that benefited institutions, but not necessarily the individuals they were intended to support. We found that many institutions offered a multitude of accommodations to support faculty; however, some institutions seemingly struggled to make such accommodations. For instance, some participants reported that no/minimal or unwanted accommodations" were provided by their university. These differences in accommodations provided may be due to varying resources from one institution to another, with some far more financially salient and able to provide a litany of support across varying needs, and others having to strategically apply limited resources to a small portion of targeted needs. Another contributing factor may be differences in leadership, with some universities focused more on the business and financial solvency of the institution as opposed to the needs and well-being of the faculty and staff. A lack of preparedness for addressing the impact of the COVID-19 pandemic certainly may have also contributed to some institutions responding with minimal, none, or unwanted accommodations for faculty.

While approximately $20 \%$ of participants expressed not needing any additional accommodations other than what had already been provided, the remaining $80 \%$ offered a range of suggested supports that would have been helpful during their institution's response to the COVID-19 pandemic. Almost half stressed the need for additional technology and system support. Also emphasized was the desire for additional teaching support and more manageable workloads. Previous research identified technology as causing disturbances and dysfunction for faculty during the pandemic (Watermeyer et al., 2020), particularly since they had to make the adjustments to an online environment immediately, often without online teaching experience or proper equipment. Based on our findings on the perceived need for greater technological support from nearly half of our sample, we infer that administrators often assumed faculty had the technology needed to teach courses from home, including computers, microphones and effective Wi-Fi at minimum, though this was not always the case. The effort needed to resolve these issues, on top of learning new technologies and transferring course content to online modalities without the necessary resources and support, translated to greater workloads and heightened stress for many. Our findings align with the extant literature which suggests that faculty workloads have increased due to additional service responsibilities and new pressures related to teaching and research (Krukowski et al., 2020; Johnson et al., 2020). These professional challenges, in combination with concerns about the virus, may be related to heightened levels of stress, and the subsequent utilization of coping strategies like physical activity, meditation, and connecting with friends and family. The COVID-19 pandemic provoked stress and uncertainty about the future regarding work and personal matters for many across the globe, which likely led to feelings of fear and anxiety (Flaherty, 2020) and subsequent new or refocused utilization of various coping skills.

More specifically, this study revealed strategies used by faculty and administrators to cope with the many challenges, changes and concerns stemming from the COVID-19 pandemic. It was found that participants managed to cope through various activities, such as working out, watching movies, and engaging with friends on Zoom. Many also relied on wellness practices such as prayer and meditation, and setting limits on exposure to the news and social media. Our findings are supported by research on coping strategies. Physical activity and mental health related activities are among the most prescribed coping mechanisms for combating stress and 
anxiety (Iqbal \& Kokash, 2011). However, new and modified coping strategies may be needed when faced with the unique stressors of a pandemic.

During the pandemic, many states completely shut down, which restricted individuals to working from their homes. For many, the pandemic resulted in major shifts in daily schedules and work habits, necessitating adjustments. Rather than taking a break from work to get lunch with a colleague or leaving the office at a set time to return home at the end of a workday, faculty and administrators needed to identify ways in which they could set boundaries on their work, fulfill social needs, and create a work-life balance despite being home almost exclusively. Specific professional practices, such as creating a separate space in their home for work, and continuing to engage in writing groups via Zoom, were identified to help reduce work stress. Institutions could play a role in providing support to faculty, such as offering online meditation sessions, scheduling online coffee hours, and providing online writing workshops. Strategic, proactive planning may have better prepared institutions to support faculty in these ways.

Participants in the present study provided insights on what they gained or learned from working remotely during the pandemic. For example, one participant shared that they have learned more about "resiliency and grace," while another noted a lesson learned about taking time away from technology. Many identified new skills and practices that they will continue post COVID-19. Almost half of participants stated that they learned new online teaching skills that they will continue to apply, even if they return to face-to-face teaching. Likewise, some participants indicated a preference to continue online meetings as opposed to face to face meetings, finding them to be more efficient and productive. In addition, faculty noted a heightened awareness of the value of engaging in self-care through both personal and professional practices. These ranged from plans to continue following set schedules to improve the work-life balance, to deliberately incorporating wellness activities in daily routines. Ultimately, many participants realized that they are quite adaptable and resilient. They also noted being more empathetic and understanding toward students as they supported their students through the pandemic.

These results shed light on some positive outcomes stemming from the pandemic, suggesting that perhaps not everything needs to return to how it was prior to COVID-19. Institutions would be wise to consider these outcomes and strategize plans for incorporating some of the modified work and teaching formats that have proven to be effective. Institutions may also consider encouraging faculty boundary setting and allowing greater flexibility with regard to responding to student challenges. A greater focus on wellness for faculty, staff, and students may positively impact productivity. Systems that prioritize the health and wellness of their employees have demonstrated positive trends in return, such as improving employee health behavior and lowering elevated health risks (Kaul, 2020). Strategic planning may assist institutions in planning for modified operations after the pandemic.

\section{Implications}

The findings from this study may be used to inform higher education strategic planning. Institutions of higher learning would benefit from adopting the strategic planning processes espoused by chaos theory. For example, according to Swenk (2001), the theory posits that institutional strategic planning processes should include steps to adequately prepare for the future, foster a culture of planning, and utilize appropriate feedback loops. Strategic planning has been identified as the best way to consider possible futures (Swenk, 2001). Planning for the 
future could include actions such as preparing reserve funding for emergencies and developing plans to pivot in case of natural disaster or similar pandemics.

The financial impact on institutions of higher education resulting from the pandemic were often severe. Inside Higher Ed's 2020 study of college and university presidents found that 53\% of campus leaders were worried about the impact the economic downturn could have on their institutions in the future. Through strategic planning, institutions can prepare to proactively decrease such negative effects when faced with future disasters or emergency situations moving forward.

If a crisis plan to provide resources to faculty, staff, and students has already been developed, institutions would be activating a plan already in existence instead of devising a plan while in the throes of the crisis. Even without this proactive stance, in the event of a pandemic, universities with "planning cultures" would be prepared for an institutional response, immediately taking action to address the needs of all parties. It is important to note that chaos theory rejects a top-down approach to strategic planning, as planning is not seen as linear (Swenk, 2001). Rather, the theory suggests a collection of plans created by each department and brought together to inform the master strategic plan (Swenk, 2001). An example of this in a university comprised of individual colleges would be each college formulating a plan, and those individual plans informing the university's master plan. COVID-19 had a major impact across the nation, and participants within this study identified accommodations that their institutions could have provided to be more helpful to them. Effective planning during the time of crisis could have been helpful in ensuring faculty received accommodations that were needed. Chaos theory advocates for creating a culture of planning which involves every stakeholder having a voice in the planning process even when responding to crises.

Moreover, institutions should consider how they might receive ongoing feedback from various stakeholders as a necessary source of information. Stakeholders should include individuals from all levels of the system: students, staff, faculty, administrators, and members of the community. Such information should be shared with all members of the institution (Swenk, 2001). Feedback is a necessary component of planning, especially in planning for the future and a possible crisis response. Pertaining to the COVID-19 pandemic, a planning culture would have captured faculty experiences very early in the process, as they would have been a part of the crisis response planning (Swenk, 2001). The inclusion of faculty experiences in the planning process could have improved the impact of accommodations on the population they were meant to support. Often, institutions were planning support without faculty input, which may have resulted in unwanted or less helpful accommodations. Future planning should capture the experiences of all stakeholders prior to and during the pandemic to inform crisis responses in higher education. These responses need to include socioemotional supports. Researchers call for institutions to adopt an ethic of care in crisis responses to minimize the emotional impact on faculty, staff and students (Corbera et. al., 2020).

\section{Limitations and Future Directions}

As with all qualitative research, it should be noted that our findings may not be generalized to all populations. The results are intended to provide insight on the lived experience of the participants in the current study. Limitations of the present study include lack of diversity in some areas including the sex and university size of participants. Notably, the majority of our participants were from large schools, which may mean their universities in general benefit from resources unavailable to those at small universities, possibly influencing the results of this study. 
Furthermore, in future studies, researchers may expand upon the current study by utilizing quantitative methods to explore broader COVID-19 impacts on faculty and administrators and their satisfaction with their institution's response to the pandemic. Future research may also focus on specific related issues, such as the incidence of anxiety and depression among higher education faculty resulting from COVID-19. This study is also limited to faculty and administrators' experiences while in the midst of the COVID-19 pandemic. It does not account for institutions' evolving response to the pandemic over time. Future research should be conducted following the pandemic to fully capture the university response to the COVID-19 pandemic and the experiences of faculty, staff and students.

In addition, op-eds were published more rapidly during the pandemic to capture and address the experiences of faculty, staff, and students. Published research on the topic was limited during the time of this publication. Future research could include a systematic review of all the studies published about university experiences and responses during the pandemic to gain a comprehensive understanding of existing gaps and to inform future institutional strategic planning. There is still a need to understand how strategic planning was used in institutions' responses to the pandemic and future research should be conducted to uncover this and inform future higher education strategic planning initiatives.

\section{Conclusion}

This study explored the experiences of faculty and staff during the COVID-19 pandemic concerning their transition to remote work. Institutional accommodations, coping strategies, and growth were integral aspects of participants' experiences. This study identified the strengths of institutional responses to the pandemic as well as challenges for participants. Through the lens of chaos theory, strategic planning may have assisted institutions in better responding to faculty needs. The results of this study can assist institutions in their current response to the pandemic, as the pandemic has not ended. Thus, providing an opportunity for institutions to adjust previous practices by applying the results and ensuring they are meeting the needs of their key stakeholders. It is critical that institutions of higher education take proactive steps to plan, now, how they will operate after the pandemic and prepare for future crises. It is suggested that institutions consider the ten propositions of chaos theory which can inform planning for the future, enabling them to shape the entire university culture toward becoming better equipped to meet the needs of all stakeholders moving forward.

\section{References}

Anderson, I., \& Alonso, G. (2020, November 25). Preparing for disruption: Strategic planning of higher education. Plante Moran. https://www.plantemoran.com/explore-ourthinking/insight/2020/11/preparing-for-disruption-strategic-planning-for-highereducation

Ayers, S. (1997). The application of chaos theory to psychology. Theory \& Psychology, 7(3), 373-398. https://doi.org/10.1177/0959354397073005

Centers for Disease Control and Prevention (2021, February 6). COVID-19 mortality overview. https://www.cdc.gov/nchs/COVID19/mortality-overview.htm

Chamberlain, L., \& Butz, M. R. (Eds.). (2016). Clinical chaos: A therapist's guide to non-linear dynamics and therapeutic change. Routledge. https://doi.org/10.4324/9781315784526

Corbera, E., Anguelovski, I., Honey-Roses, J., \& Ruiz-Mallen, I. (2020). Academia in the time of COVID-19: Towards an ethics of care. Planning Theory \& Practice, 21(2), 191-199. 
https://doi.org/10.1080/14649357.2020.1757891

Cui, R., Ding, H., \& Zhu, F. (2020). Gender inequality in research productivity during the COVID-19 pandemic. Social Science Research Network, 1-25. https://papers.ssrn.com/sol3/papers.cfm?abstract id=3623492

Cutright, M. (2001). Chaos Theory \& Higher Education: Leadership, Planning, \& Policy. Higher Education: Questions about the Purpose (s) of Colleges \& Universities. Volume 9. Peter Lang Publishing, Inc. https://doi.org/10.1023/A:1017978827715

Elliott, R., Fischer, C. T., \& Rennie, D. L. (1999). Evolving guidelines for publications of qualitative research studies in psychology and related fields. British Journal of Clinical Psychology, 38(3), 215-299. https://doi.org/10.1348/014466599162782

Entangled Solutions. (2020). COVID-19: Higher education resource center-Entangled solutions. (2020). Entangled Solutions - An Ecosystem Approach To Advancing Education. https://www.entangled.solutions/coronavirus-he/

Fauci, A. S., Lane, C., \& Redfield, R. R. (2020). COVID-19--Navigating the uncharted. The New England Journal of Medicine, 382, 1268-1269. https://doi.org/10.1056/NEJMe2002387

Flaherty, C. (2020, November 19). Faculty pandemic stress is now chronic. https://www.insidehighered.com/news/2020/11/19/faculty-pandemic-stress-now-chronic

Goldman, C.A., \& Salem, H. (2015). Getting the most out of university strategic planning: Essential guidance for success and obstacles to avoid. Rand Corporation. www.rand.org

Hinton, K. E. (2012). A practical guide to strategic planning in higher education. Society for College and University Planning. www.scup.org

Holmes, E. A., O'Connor, R. C., Perry, V. H., Tracey, I., Wessely, S., Arseneault, L., ... \& Ford, T. (2020). Multidisciplinary research priorities for the COVID-19 pandemic: A call for action for mental health science. The Lancet Psychiatry, 7(6), 547-560. https://doi.org/10.1016/S2215-0366(20)30168-1

Hsieh, H. F. \& Shannon, S. E. (2005). Three approaches to qualitative content analysis. Qualitative Health Research, 15(9), 1277-1288.

Hunt, B. (2011). Publishing qualitative research in counseling journals. Journal of Counseling and Development, 89(3), 296-300. https://doi.org/10.1002/j.1556-6678.2011.tb00092.x

Inside Higher Ed. (2020). Inside Higher Ed 2020 Survey of College and University Presidents. https://www.insidehighered.com/system/files/media/20200313 Presidents_Survey_Origi nal new.pdf

Iqbal, A., \& Kokash, H. (2011). Faculty perception of stress and coping strategies in a Saudi private university: An exploratory study. International Education Studies, 4(3), 137-149. https://doi.org/10.5539/ies.v4n3p137

Johnson, N., Veletsianos, G., \& Seaman, J. (2020). U.S. faculty and administrators' experiences and approaches in the early weeks of the COVID-19 pandemic. Online Learning, 24(2), 6-21. https://doi.org/10.24059/olj.v24i2.2285

Kaul, A. (2020, March 5). Benefits of Corporate Wellness Program. Entrepreneur. https://www.entrepreneur.com/article/347207

Krukowski, R. A., Jagsi, R., \& Cardel, M. I. (2020). Academic productivity differences by gender and child age in science, technology, engineering, mathematics, and medicine faculty during the COVID-19 pandemic. Journal of Women's Health. https://doi.org/10.1089/jwh.2020.8710

Nutefall, J. E. (2015). How an outside facilitator helped us create a better strategic plan. University Library, 28. http://scholarcommons.scu.edu/library/28 
Parker, K., Minkin, R., \& Bennett, J. (2020, October 30). Economic fallout from COVID-19 continues to hit lower-income Americans the hardest. https://www.pewsocialtrends.org/2020/09/24/economic-fallout-from-COVID-19continues-to-hit-lower-income-americans-the-hardest/

Pfefferbaum, B., \& North, C. S. (2020). Mental health and the COVID-19 pandemic. The New England Journal of Medicine, 383(6), 510-512. https://doi.org/10.1056/NEJMp2008017

Roy, D., Tripathy, S., Kar, S. J., Sharma, N., Verma, S. K., \& Kaushal, V. (2020). Study of knowledge, attitude, anxiety \& perceived mental healthcare need in Indian population during COVID-19 pandemic. Asian Journal of Psychiatry, 51, 1-7. https://doi.org/10.1016/j.ajp.2020.102083

Swenk, J. P. (2001). Strategic planning and Chaos Theory: are they compatible. Chaos Theory and higher education: Leadership, planning, and policy, 33-56.

Torales, J., O’Higgins, M., Castaldelli-Maia, J. M., \& Ventriglio, A. (2020). The outbreak of COVID-19 coronavirus and its impact on global mental health. International Journal of Social Psychiatry, 66(4), 317-320. https://doi.org/10.1177/0020764020915212

von Braun, J., Zamagni, S., \& Sanchez Sorondo, M. (2020). The moment to see the poor. Science, 368(6488), 214. https://doi.org/10.1126/science.abc2255

Watermeyer, R., Crick, T., Knight, C., \& Goodall, J. (2020). COVID-19 and digital disruption in UK universities: Afflictions and affordances of emergency online migration. Higher Education, 1. https://doi.org/10.1007/s10734-020-00561-y

World Health Organization. (2020, January 30). Pneumonia of unknown cause - China. Retrieved September 28, 2020, from https://www.who.int/csr/don/05-january-2020pneumonia-of-unkown-cause-china/en/

Zenker, S., \& Kock, F. (2020). The coronavirus pandemic-A critical discussion of a tourism research agenda. Tourism management, 81, 104-164. https://doi.org/10.1016/j.tourman.2020.104164

Zhang, Y. \& Wildemuth, B. M. (2005). Qualitative analysis of content. Human Brain Mapping, 30(7), 2197-2206. 
Theme Code Book by Question

\section{Appendix}

\begin{tabular}{|c|c|c|}
\hline Code & Freq. & $\%$ \\
\hline $\begin{array}{l}\text { 1. Professional Adaptations } \\
\text { Teaching adaptations } \\
\cdot \text { Online teaching trainings } \\
\cdot \text { Teaching Format } \\
\text { o Choice to teach F2F, hybrid, online } \\
\text { o Teach online with documented accommodations } \\
\text { o Fully online } \\
\text { o Smaller class sizes } \\
\text { Work adaptations } \\
\cdot \text { Remote work } \\
\cdot \text { Flexibility } \\
\text { o Extend the clock for tenure and pre-tenure review } \\
\text { o Not counting course evaluations } \\
\text { o Extended deadlines/extra time for grading } \\
\text { o Accommodating those with children }\end{array}$ & $\begin{array}{c}151 \\
79 \\
34 \\
45 \\
31 \\
11 \\
2 \\
1 \\
72 \\
33 \\
39 \\
\\
23 \\
4 \\
9 \\
3\end{array}$ & 53.4 \\
\hline $\begin{array}{l}\text { 2. Professional Supports } \\
\text { Technology resources } \\
\cdot \quad \text { Equipment (mics, headsets, cameras, hot spots, } \\
\text { laptops, Zoom, online textbooks) } \\
\text {. } \quad \text { Support (troubleshooting and trainings) } \\
\text { Information } \\
\cdot \quad \text { From admin (meetings, emails, understanding, } \\
\text { flexibility) } \\
\cdot \quad \text { From colleagues } \\
\cdot \quad \text { Mental health support workshops } \\
\text { Materials } \\
\cdot \quad \text { Office supplies sent to home } \\
\cdot \quad \text { Access to office phone calls } \\
\text {. } 1 \text { day off per week } \\
\cdot \quad \text { COVID resources } \\
\text { o Masks/PPE } \\
\text { o Testing } \\
\text { o Social distancing } \\
\text { Funding } \\
\cdot \quad \text { Stipends } \\
\cdot \quad \text { Reimbursements for supplies } \\
\cdot \quad \text { Reimbursement for personal phone bill } \\
\cdot \quad \text { Emergency sick leave fund }\end{array}$ & $\begin{array}{c}14 \\
3 \\
1 \\
1 \\
9 \\
6 \\
1 \\
2 \\
7 \\
3 \\
2 \\
1 \\
1\end{array}$ & 33.6 \\
\hline
\end{tabular}


3. None/minimal/unwanted

None provided

Already teach/work online

Must teach online

Not allowed on campus without permission

More work

\begin{tabular}{c|c|c} 
& 37 & 13.0 \\
& 25 & \\
6 & \\
1 & \\
& 3 & \\
& 2 & \\
& & \\
\hline Total & 283 & 100 \\
\hline
\end{tabular}

Q2: What accommodations would be helpful that have not been provided?

\begin{tabular}{|c|c|c|}
\hline Code & Freq. & $\%$ \\
\hline $\begin{array}{l}\text { 1. Technology } \\
\text { Resources/equipment } \\
\text { Support/trainings } \\
\text { Support for students (Wi-Fi, laptops) }\end{array}$ & $\begin{array}{l}36 \\
25 \\
9 \\
2\end{array}$ & 25.5 \\
\hline $\begin{array}{l}\text { 2. Enhanced system support } \\
\text { Mental health support } \\
\text { Better communication/instructions/information from leaders } \\
\text { Faculty input in decisions } \\
\text { Better support from support staff } \\
\text { Safe access to offices/labs } \\
\text { PPE, cleaning supplies } \\
\text { Financial Support } \\
\text {. Not being furloughed/laid off } \\
\text {. Insurance for adjuncts } \\
\text {. Stipends/reimbursements }\end{array}$ & $\begin{array}{l}33 \\
8 \\
10 \\
1 \\
1 \\
2 \\
4 \\
7 \\
2 \\
1 \\
4\end{array}$ & 23.4 \\
\hline 3. None needed/not sure & 27 & 19.1 \\
\hline $\begin{array}{l}\text { 4. Manageable workload } \\
\text { Support with balancing childcare and work } \\
\text { Pause P\&T clock } \\
\text { Reduce nonessential work, service load and meetings so more } \\
\text { time for adjusting to online and maintaining research }\end{array}$ & $\begin{array}{l}23 \\
11 \\
3 \\
9\end{array}$ & 16.3 \\
\hline
\end{tabular}


5. Teaching

Online teaching training

GAs/Tas/support

Choice of teaching modality

All classrooms Zoom capable

Assistance addressing field placements

More collaboration

Reduce course load

More time to grade

\begin{tabular}{r|c|c} 
More time to grade & 1 & \\
\hline Total & 141 & 100 \\
\hline
\end{tabular}

Q3: Coping strategies utilized

\begin{tabular}{|c|c|c|}
\hline Code & Freq. & $\%$ \\
\hline 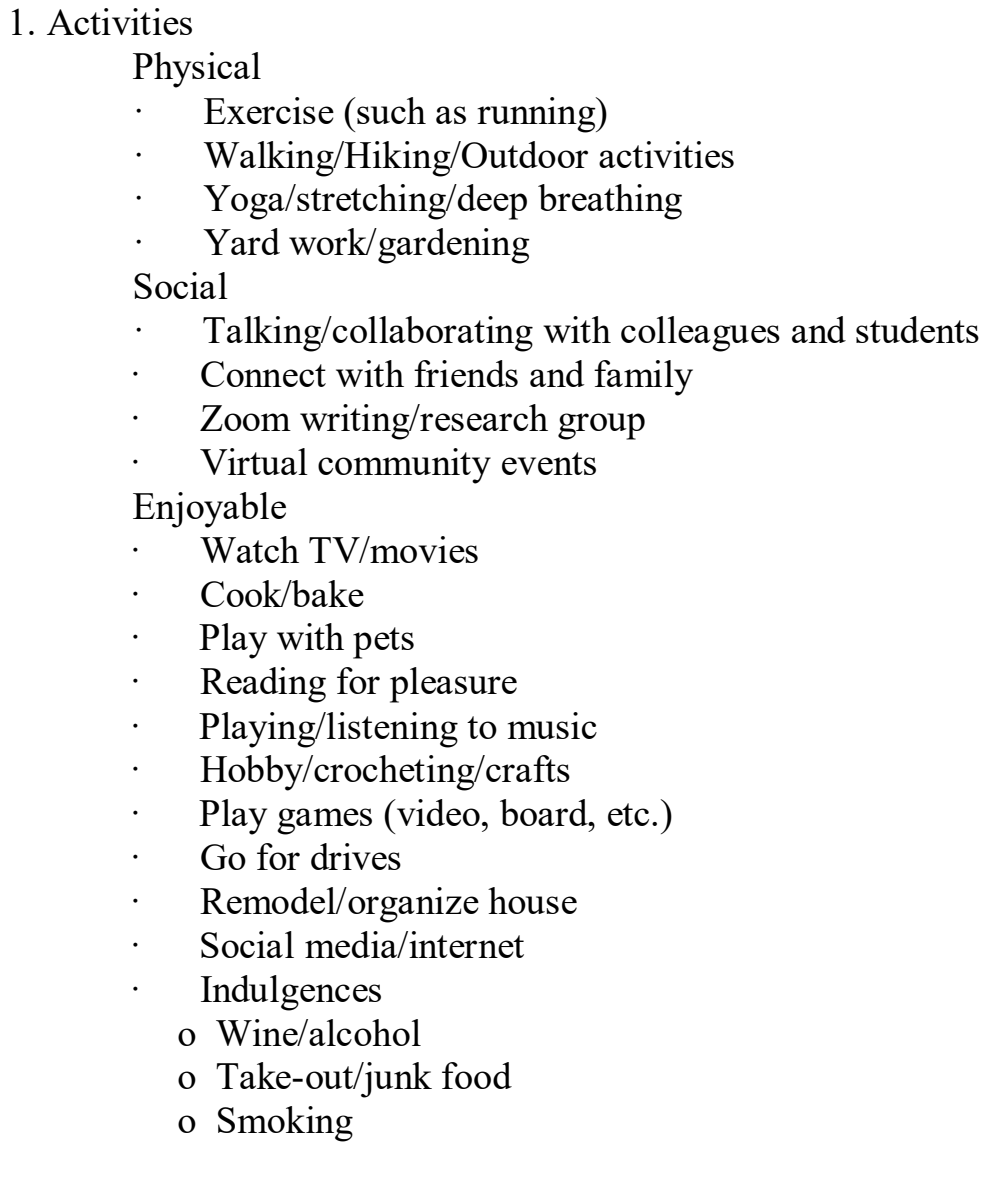 & $\begin{array}{c}219 \\
111 \\
49 \\
43 \\
17 \\
2 \\
45 \\
12 \\
\\
28 \\
4 \\
1 \\
63 \\
7 \\
6 \\
6 \\
7 \\
6 \\
6 \\
4 \\
2 \\
2 \\
3 \\
14 \\
6 \\
7 \\
1\end{array}$ & 58.9 \\
\hline
\end{tabular}


2. Mental health boosters

Taking breaks!

Prayer

Meditation

Antidepressant/antianxiety medication

Naps

Therapy

Practice patience \& gratitude/self-talk/self-compassion/selfcare/crying/relax goals Avoiding the news/disconnecting/limiting TV/not checking email during certain times Humor

3. Work habits

Follow a schedule/routine/put boundaries on workday Creating a separate space in house for work Got improved internet Managing Children

Got assistance (babysitter or sharing children's responsibilities with spouse)

Allow more screen time

- Send to daycare

4. Not using any/no need

\begin{tabular}{|c|c|c|}
\hline 4. Not using any/no need & 11 & 3.0 \\
\hline Total & 372 & 100 \\
\hline
\end{tabular}

Q4: Skills, attitudes, idea gained that you will continue post-pandemic

\begin{tabular}{l|c|c}
\hline \multicolumn{1}{c|}{ Code } & Freq. & $\%$ \\
\hline 1. Teaching skills & 89 & 48.9 \\
More flexibility with students/more connections with students & 32 & \\
Use of more online teaching tools regardless of format & 45 & \\
Will teach more online courses & 10 & \\
learned that do not want to teach online & 2 & \\
& 55 & 30.0 \\
2. Professional insights & 28 & \\
More use of zoom/online meetings rather than in-person or in & 13 & \\
addition to & 8 & \\
Apply scheduling/organization to day/boundaries & 2 & \\
Will work more from home & 1 & \\
Learned that cannot work well from home & 3 & \\
Continue to use digitized processes (signing forms) &
\end{tabular}


Sparkman-Key et al: Institutional Responses to the COVID-19 Pandemic

\begin{tabular}{|c|c|c|}
\hline $\begin{array}{l}\text { 3. Personal insights } \\
\text { Crisis response skills/being adaptive/staying positive/self- } \\
\text { care/less hard on self } \\
\text { Importance of connecting with people } \\
\text { More use of fun activities in life } \\
\text { More use of telehealth }\end{array}$ & $\begin{array}{l}38 \\
26 \\
7 \\
3 \\
2\end{array}$ & 20.1 \\
\hline Total & 182 & 100 \\
\hline
\end{tabular}

Note. Since many responses had more than one code applied to them, the total frequency will be more than the total number of respondents. 


\section{Author Notes}

Narketta Sparkman-Key

Old Dominion University

nsparkma@odu.edu

https://orcid.org/0000-0002-1438-6704

Tammi F. Dice

Old Dominion University

tmillike@odu.edu

https://orcid.org/0000-0002-1754-6232

Alexandra C. Gantt

Old Dominion University

agant002@odu.edu

https://orcid.org/0000-0002-0889-2109

Cc (7) (2) More details of this Creative Commons license are available at https://creativecommons.org/licenses/by-sa/4.0/. Current Issues in

Education is published by the Mary Lou Fulton Institute and Graduate School of Education at Arizona State University.

\section{ASI' 'Maryour futhon College}

Arizona State University 